\title{
Treatment of Displaced Middle Third Clavicle Fracture with Precontoured Clavicular Locking Plate
}

\author{
RAM Kausarul Islam ${ }^{1 *}$, Mizanur Rahman ${ }^{2}$
}

${ }^{1}$ Assistant Professor, Department of Orthopaedic Surgery, National Institute of Traumatology and Orthopaedic Rehabilitation (NITOR), Dhaka, Bangladesh

${ }^{2}$ Assistant Professor, Department of Orthopaedic Surgery, Faridpur Medical College, Faridpur, Bangladesh

*Corresponding author: Dr. RAM Kausarul Islam

\section{Abstract}

Background: A clavicle fracture, also known as a broken collarbone, is a bone fracture of the clavicle. Symptoms typically include pain at the site of the break and a decreased ability to move the affected arm. It accounts about $2.6 \%$ of all fractures in adult and $44 \%$ in shoulder region. Midshaft clavicle fractures accounts about $81 \%$ of total clavicle fractures. Aims \& Objectives: The study aimed to evaluate the outcome of surgical management of displaced midshaft clavicle fracture with precontoured locking plate. Materials \& Methods: A prospective study was conducted in four (4) selected hospitals like National Institute of Traumatology and Orthopaedic Rehabilitation (NITOR), Dhaka, Bangladesh, Care Medical College Hospital, College Gate, Dhaka, Bangladesh, Bangladesh Spine \& Orthopedic Hospital, Dhaka, Bangladesh and Ekota - Bandhan General Hospital, Sherpur, Bangladesh during the period from June 2017 to December 2019. Thirty two (32) patients were selected as study participants from the selected hospitals. All the participants had displaced midshaft clavicle fracture and treated by ORIF with pre-contoured locking plate. The data entry was immediately after completion of data collection. Data processing and analysis was done using SPSS Version 19. Data were analyzed according to the objectives of the study. Results: Thirty two (32) cases of clavicle fracture were treated with precontoured locking plate under general anaesthesia. Among all $30(93.75 \%)$ were male and $2(6.25 \%)$ were female. The age range was 21 to 48 years. There were 23 left and 9 right sided clavicle fractures. In 12 patients the fractures were comminuted. The mode of injury were RTA in 17 cases, fall from height in 8 and sport injury in 7 cases. There were only 2 cases with type I open fracture. All the fracture united with good alignment and shoulder function. The functional outcome according to Constant Murley Scores (CMS) were excellent in 20 $(62.50 \%)$ cases and good in $12(37.50 \%)$ cases. Clinical union was considered when the patient had painless movement of the shoulder. The average time duration for clinical union in our study was 12 weeks. There were not any major complication in our study. Conclusion: Open reduction and internal fixation with precontoured locking plate is a good option for displaced midshaft clavicle fracture. It provides immediate pain relief and prevents complications like non-union, mal-union and shoulder stiffness.

Keywords: Clavicle fracture, Precontoured Clavicular Locking Plate, Midshaft.

Copyright @ 2020: This is an open-access article distributed under the terms of the Creative Commons Attribution license which permits unrestricted use, distribution, and reproduction in any medium for non-commercial use (NonCommercial, or CC-BY-NC) provided the original author and source are credited.

\section{INTRODUCTION}

A clavicle fracture, also known as a broken collarbone, is a bone fracture of the clavicle. Symptoms typically include pain at the site of the break and a decreased ability to move the affected arm. It accounts about $2.6 \%$ of all fractures in adult and $44 \%$ in shoulder region. Midshaft clavicle fractures accounts about $81 \%$ of total clavicle fractures. It was traditionally treated conservatively but open reduction and internal fixation with pre-contoured locking plate is a good option for displaced midshaft fracture with benefit of early pain free movement of shoulder joint. The most commonly applied system of classification of clavicular fractures is that of Allman. All the data, however, are based on studies in which clavicle fractures were not adequately classified regarding patient's age and fracture displacement grade. More recent data, based on detailed classification of fractures, suggest that the incidence of nonunion in displaced comminuted midshaft clavicular fractures in adults is between 10 and $15 \%$ [1]. Also persistent wide separation of fragments with interposition of soft tissue may lead to failure of closed reduction. There is $15 \%$ nonunion rate in widely displaced fractures of middle-third of the clavicle treated without surgery. And all fractures with initial shortening of more than $2 \mathrm{~cm}$ resulted in nonunion [2]. Fractures of the mid shaft of the clavicle account for 
about $80 \%$ of all the clavicular fractures. $2-5 \%$ of all the fractures in the adults and $10-15 \%$ in children are estimated to be due to fractures of the clavicle [3]. Plate fixation has been advocated to be one of the useful options for fracture treatment [4]. Low contact dynamic compression plates are strong but difficult to contour, thereby causing irritation of the soft tissue. On the other hand, reconstructed plates have the capacity to contour easily but they are not mechanically strong. A better option is the pre-contoured locking plates which provide immediate relief, stabilization and early mobilization, more so because they do not require further bending. They are also known to cause fewer soft tissue problems. Several studies have examined the safety and efficacy of primary open reduction and internal fixation for completely displaced midshaft clavicular fractures and have noted high union rate with a low complication rate [5]. In a large number of complex clavicle fractures a satisfactory outcome is possible with a low complication rate using a locked compression plate [6]. Primary internal fixation of displaced comminuted mid-shaft clavicular fractures leads to predictable and early return to function [7]. While the overwhelming majority of clavicle fractures are benign, associated life-threatening intrathoracic injuries are possible. Complications vary based on location of fracture [8]. Fracture of the clavicle is associated with delayed union or nonunion [9], brachial plexus compression resulting from hypertrophic callus formation, compression or laceration of the great vessels, trachea, or esophagus, injuries to the neurovascular bundle and the pleural dome, poor cosmetic appearance, pneumothorax and intra-thoracic injury. There are various plates including Sherman plates, Dynamic compression plates and Semi tubular plates. Among them reconstruction plate and Anatomical locking compression plate (LCP) are more useful. We have conducted this study to gain a deeper understanding of results and complications associated with this procedure to evaluate the functional outcome after fixation of displaced clavicular fractures with locking compression plate.

\section{Methodology \& Materials}

This was a prospective type of study conducted in four (4) selected hospitals like National Institute of Traumatology and Orthopaedic Rehabilitation (NITOR), Dhaka, Bangladesh, Care Medical College Hospital, College Gate, Dhaka, Bangladesh, Bangladesh Spine \& Orthopedic Hospital, Dhaka, Bangladesh and Ekota-Bandhan General Hospital, Sherpur, Bangladesh during the period from June 2017 to December 2019. Our aim was to evaluate the treatment of displaced middle third clavicle fracture with pre contoured clavicular locking plate. All the participants had displaced midshaft clavicle fracture and treated by ORIF with pre-contoured locking plate. All of the patients were treated with open reduction and internal fixation of the clavicle with a pre-contoured superior clavicle locking plate. According to the inclusion criteria of the study patients of age between 21-48 years old, either sex, comminuted, displaced (larger than $2 \mathrm{~cm}$ ), shortening (Larger than $2 \mathrm{~cm}$ ), segmental fractures, fractures with tenting of skin were included. On the other hand, according to the exclusion criteria, patients with associated injuries of the shoulder girdle, open fractures, pathological fractures, established non-union from previous fracture, noncompliant or substance abusers were excluded. Moreover, clinically important neuromuscular upper limb disability previous operations to shoulder or clavicle previous fractures around the clavicle medically unfit for surgery cases were excluded. The implant applied in all our patients was a pre-contoured $3.5 \mathrm{~mm}$ superior clavicle locking compression plate. Another set of $2.7 \mathrm{~mm}$ lag screws was always kept ready, in order to lag any unstable butterfly fragment(s), if the need arose. The proper written informed consent was received from all the patients for their participation in this study. All the patients were explained in detail the available methods of treatment, with the final treatment decision left to the patient. Proper history of the patient was taken, ascertaining the mode of injury, with particular emphasis placed on ruling out injuries to other areas. AP views of the involved shoulder and $20^{\circ}$ cranial views were taken, so as to have a full visualization of the clavicle. All the surgeries were performed under general anaesthesia. The patients were positioned in either the supine, with the head and neck tilted away from the surgical site with a bump placed behind the scapula to aid in reduction. The arm was prepared in the field to allow for traction and manipulation to assist in the reduction. Pre-operative intra-venous antibiotic was given to the patient, at least 30 minutes before making the skin incision. A direct insetion was made over the clavical. The subcutaneous tissue and platysma muscle were kept together as one layer and extensively mobilized, especially proximally and distally. Sharp dissection was taken down to the bone, with care to identify, and if possible, preserve the cutaneous supraclavicular nerves. When deemed necessary, they were sacrificed. The myofascial layer over the clavicle was incised and elevated in one continuous layer. Comminuted fragments, especially the often seen antero-superior fragment was teased back into position, as much as possible, maintaining its soft tissue attachments. At least 4 cortices on either side of the fracture were held by cortical screws. Once plating was completed, the fascia was repaired over the plate. Skin incision was closed. Antiseptic dressing was applied, and the arm was rested in an arm sling. Then the patient was kept in the post-operative recovery ward, under observation. Vitals were monitored pendulum exercises of the shoulder were started, with the arm still rested in the arm sling. The patient was discharged on the second post-operative day, and intravenous antibiotics were stopped on the same day. All patients were followed up at 2 weeks, 6 weeks, 12 weeks, and 6 months. Finally according to the Constant Murley Scoring system outcomes were assessed. The 
data entry was immediately after completion of data collection. Data processing and analysis was done using SPSS Version 19. Data were analyzed according to the objectives of the study.

\section{RESULTS}

In this study, thirty two (32) subjects were included. The main indications for surgery were displacement, shortening and comminuted fractures. Among them $46.88 \%, 34.38 \%$, and $18.75 \%$ were from $31-40,21-30$ and 41-48 years' age group respectively. Most of the cases were male which $93.75 \%$ was and female were $6.25 \%$. In analyzing the mode of injury we found, $53.13 \% 25 \%$, and $21.88 \%$ mode of injuries were RTA, fall from height and sport injury respectively. In our study, in $71.88 \%$ cases left side and in $28.13 \%$ cases right side were involved. In analyzing the treatment duration for union we found the highest $47 \%$ cases taken 11-12 weeks for radiological union. Then $28 \%$, $16 \%$ and $9 \%$ taken $9-10,>12$ and $<8$ weeks respectively. According to the Constant Murley Score (CMS) as final outcome we found maximum patients got 'Excellent' result which was $62.50 \%$ and the rest $37.5 \%$ got 'Good' result. About minor complications, we found the highest $33.33 \%$ patients suffered from dysesthesia and then $22.22 \%, 11.11 \% \quad 11.11 \%$ and another $22.22 \%$ suffered from superficial infection, plate pullout, plate loosening and hardware irritation respectively. There was a $100 \%$ clinical evidence of radiological union rate within an average period of 12 weeks. One patient re-fractured the clavicle with the plate in-situ after seven weeks due to fall with an out stretch hand and his fracture had been united after 18 weeks through conservative treatment. Almost all the patients returned to work after an average sick leave of 10 weeks ( 8 weeks to 6 months).

Table-1: General characteristics of participants $(\mathrm{N}=32)$

\begin{tabular}{|l|l|l|}
\hline Characteristics & n & \% \\
\hline Age (Years) & \multicolumn{3}{|l|}{} \\
\hline $21-30$ & 11 & $34.38 \%$ \\
\hline $31-40$ & 15 & $46.88 \%$ \\
\hline $41-48$ & 6 & $18.75 \%$ \\
\hline Gender & 30 & $93.75 \%$ \\
\hline Males & 2 & $6.25 \%$ \\
\hline Females & \multicolumn{3}{|l}{} \\
\hline Mode of injury \\
\hline RTA & 17 & $53.13 \%$ \\
\hline Fall from height & 8 & $25.00 \%$ \\
\hline Sport injury & 7 & $21.88 \%$ \\
\hline Side involved & 9 \\
\hline Right & 9 & $28.13 \%$ \\
\hline Left & 23 & $71.88 \%$ \\
\hline
\end{tabular}

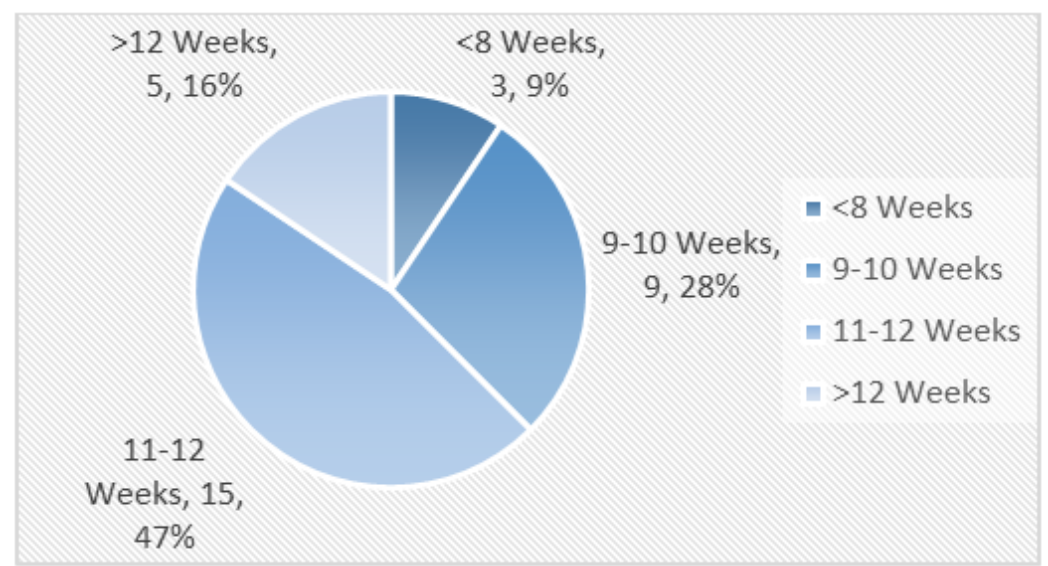

Fig-1: Treatment duration for radiological union of participants ( $N=32)$

Table-2: Final outcome of participants according to CMS ( $N=32)$

\begin{tabular}{|l|l|l|}
\hline Score & $\mathrm{n}$ & $\%$ \\
\hline Excellent & 20 & $62.50 \%$ \\
\hline Good & 12 & $37.50 \%$ \\
\hline
\end{tabular}


Table-3: Minor complications among the participants $(\mathrm{N}=09)$

\begin{tabular}{|l|l|l|}
\hline Complication & $\mathrm{n}$ & $\%$ \\
\hline Dysesthesia & 3 & $33.33 \%$ \\
\hline Superficial infection & 2 & $22.22 \%$ \\
\hline Plate pullout & 1 & $11.11 \%$ \\
\hline Plate loosening & 1 & $11.11 \%$ \\
\hline Hardware irritation & 2 & $22.22 \%$ \\
\hline
\end{tabular}

\section{DISCUSSION}

Clavicle fractures are generally treated conservatively. In a study conducted to analyze the results of conservative treatment by Robinson et al., [10] in 2004 found poor results following conservative treatment of displaced middle third clavicle fracture. There were specific indications like displacement, with or without comminuted middle third clavicle fracture (Robinson Type-2B1, 2B2). The present study of patients with comminuted midshaft clavicle fractures is compared with Bostman et al., [11] study which treated middle third clavicle fractures. In that study totally 103 patients were treated by early open reduction and internal fixation with plate and screws. It was also compared with Cho et al., [12] study where 41 patients with a clavicle midshaft fracture were treated by internal fixation with a reconstruction plate (19 patients) or reconstruction LCP (22patients). In our prospective study 30 patients were male whereas only 2 patients were female. In Bostman et al ${ }^{11}$ series also commonly males are affected 76 Patients $(73.79 \%)$ compared to females 27 Patients (26.21\%). In Cho et al ${ }^{12}$ study, the reconstruction plate group that 12 male and 7 female Patients and in the locking compression plate group it was 17 male and 5 patients were female. So male were dominating in number in all the studies. In this present study, Robinson Type-2 B1 (Displaced with simple or butterfly fragment) were more common. In Bostman et al., [11] study also Robinson type-2B1 was common in 81 patients $(78.64 \%)$. Robinson type-2 B2 occurred only in 22 patients $(21.36 \%)$. In Cho et al., [12] study, in reconstruction plate group there were 7 Patients with B1 type and 12 Patients with B2 type and that of the locking compression group had 9 B1 type and 13 B2type. In our study all patients were operated within 4 days of admission. In Bostman et al., [11] study all the patients were operated within 3 days of injury. In Cho et al., [12] study, the reconstruction plate group was operated by 4 days and that of locking compression plate was 9 days. In analyzing the treatment duration for union we found the highest $47 \%$ cases taken 11-12 weeks for radiological union. Then $28 \%, 16 \%$ and $9 \%$ taken $9-10,>12$ and $<8$ weeks respectively. There were no non-union. Lazarus MD [13] stated radiological union occurred approximately between 6 to 12 weeks. In Cho et al., [12] study, bony union for reconstruction plate was 14.6 weeks and that of locking compression plate was 13.2 weeks. In this study in analyzing the complications of this treatment procedure we found, the highest $15.63 \%$ patients suffered from dysesthesia as a complication. Besides this, 6.25\%, 6.25\% (Another
$6.25 \%), 3.13 \%$ and another $6.25 \%$ suffered from superficial infection, plate pullout, plate loosening and hardware irritation respectively. There were no major complications in this study. Both Bostman et al., and Cho et al., [12] didn't have any major complications either. Plate loosening occurred in only 1 patient at the end of 4 weeks postoperatively. The cause in this patient was also due to non-compliance with the postoperative protocol. With further advice of not to lift heavy weights in the affected limb clavicle fracture went to unite in mal position at end of 12 weeks and no reoperation was performed for this. In Bostman et al., [11] study 7 patients $(6.80 \%)$ had implant loosening. In all the patients loosening occurred at 6 postoperative weeks. Mal-union of varying degree followed in all of these patients and no reoperations were performed. In Cho et al., study [12], only there construction group that plate loosening in 3 patients $(15.8 \%)$. According to the Constant Murley Score (CMS) as final outcome we found maximum patients got 'Excellent' result which was $62.50 \%$ and the rest $37.5 \%$ got 'Good' result. These outcome was better than other studies we had studied.

\section{LIMITATIONS OF THE STUDY}

This was a single centered study with a small sized sample. So the findings of this study may not reflect the exact scenario of the whole country.

\section{CONCLUSION AND \\ RECOMMENDATIONS}

Open reduction and internal fixation with precontoured locking plate provides immediate pain relief, early return to work and prevents complications like non-union, mal-union and shoulder stiffness. Operative treatment of clavicle fractures generally have good functional outcome. The advantages of anatomical locking compression plate include strong fixation due to locking between the screw and plate, and blood supply preservation due to minimal contact between plate and cortical bone. For getting more specific findings we would like to recommend for conducting more studies regarding the same issue with larger sized sample.

\section{REFERENCES}

1. Wun-Jer S, Tsung-Jen L, Young-Shung S. PoCheng Orthopaedic Institute, 100 Po-Ai 2nd Road, Kaohsiung, 813, Taiwan. Plate Fixation of Fresh 
Displaced Midshaft Clavicle Fractures, J Bone Joint Surg [Br]. 2008; 90- B:1495-B

2. Terry CS, James HB. Campbell's Operative Orthopedics 11th Edition, 3, 3371-3376.

3. Robinson CM. Fractures of the clavicle in the adult. Epidemiology and Classification. J Bone Joint Surg Br, 1998; 80:476-84.

4. Ring D, Jupiter JB, Miller ME, Ada JR. Injuries to the shoulder girdle: part II. Fractures of the clavicle. In: Browner BD, Jupiter JB, Levine AM, Trafton PG, (eds). Skeletal trauma. Volume 2. Philadelphia: WB Saunders; 1998: 1670.

5. Holbrook TL. The Frequency of Occurrence, Impact, and Cost of Selected Musculoskeletal Conditions in the United States. Chicago, Ill.: American Academy of Orthopaedic Surgeons, 1984.

6. Robinson CM. Fractures of the clavicle in the adult. Epidemiology and classification. J Bone Joint Surg Br. 1998; 80:476-84.

7. Neer CS. Nonunion of the clavicle. JAMA. 1960; 172:1006-11.

8. Hill JM, McGuire MH, Crosby L. Closed treatment of displaced middle-third fractures of the clavicle gives poor results. J Bone Joint Surg (Br). 1997; 79:5.

9. Boehme D, Curtis RJ, DeHaan JT. Nonunion of fractures of the mid-shaft clavicle. J Bone Joint Surg (Am). 1991;73:1219-26.

10. Robinson CM, Court Brown CM, McQueen MM, Walkefield AE. Estimating the risk of non-union following non operative treatment of a clavicular fracture. J Bone Joint Surgery (Am). 2004; 86:1359- 1365

11. Bostman O, Manninen M, Pihlajamaki $H$. Complications of plate fixation in fresh displaced mid clavicular fractures. J Trauma. 1997; 43:778783.

12. Chul-Hyun C, Kwang-Soon S, Byung-Woo M, KiCheor B, Kyung-Jae L. Reconstruction Plate versus Reconstruction Locking Compression Plate for Clavicle Fractures. Clinics in Orthopedic Surgery. 2010: 2:154-159.

13. Lazarus. Fractures of the Clavicle. Chapter-26, In: Bucholz RW and Heckman JD, editors, Rockwood and Green's fractures in adults, 5thedition, Philadelphia: Lippincott Williams and Wilkins, 2001, 1041-1078. 